\title{
Avaliação do impacto da variação da renda no consumo domiciliar de água
}

\section{Evaluation of the income variation impact on household water consumption}

\author{
David Montero Dias \\ Engenheiro Civil pela Universidade Federal do Rio de Janeiro (UFRJ). Mestre em Saneamento, Meio Ambiente e Recursos Hídricos pela Universidade \\ Federal de Minas Gerais (UFMG). Analista de Planejamento do Instituto Brasileiro de Geografia e Estatística (IBGE)

\section{Carlos Barreira Martinez} \\ Engenheiro Civil pela Faculdade de Engenharia Civil de Itajubá (FECI). Mestre em Engenharia Mecânica e Doutor em Planejamento Energético pela \\ Universidade Estadual de Campinas (Unicamp). Coordenador do Centro de Pesquisas Hidráulicas e Recursos Hídricos da UFMG. Professor Associado do \\ Departamento de Engenharia Hidráulica e Recursos Hídricos da UFMG
}

\section{Marcelo Libânio}

Engenheiro Civil e Mestre em Engenharia Sanitária pela UFMG. Doutor em Hidráulica e Saneamento pela Universidade de São Paulo (USP). Pós-doutorado pela Universidade de Alberta (Canadá). Pesquisador do Conselho Nacional de Desenvolvimento Científico e Tecnológico (CNPq) e da Fundação de Amparo à

Pesquisa do Estado de Minas Gerais (Fapemig). Professor Associado do Departamento de Engenharia Hidráulica e Recursos Hídricos da UFMG

\section{Resumo}

Este trabalho objetivou avaliar o impacto que a alteração da renda das famílias exerce sobre o consumo de água tratada fornecida pela concessionária (no caso, a Companhia de Saneamento de Minas Gerias - Copasa) no município de Belo Horizonte, ao longo de um histórico de 35 meses, abrangendo o período de agosto de 2003 a junho de 2006. Para tal, utilizaram-se dados da Pesquisa Mensal de Emprego (PME) do Instituto Brasileiro de Geografia e Estatística (IBGE), englobando 3.100 domicílios e 10.200 moradores, e os consumos residenciais micromedidos dos 6 distritos operacionais da Copasa. Os dados foram observados em seus períodos de forma que houvesse a compatibilização cronológica entre os mesmos. Os resultados mostraram relação intrínseca entre o consumo per capita e a renda mensal, balizados pelos gráficos de dispersão e pelos significativos coeficientes de determinação obtidos (superiores a 0,8), além do prognóstico de saturação do consumo demonstrado para classes sociais economicamente mais favorecidas.

Palavras-chave: consumo de água; consumo domiciliar de água; sistema de abastecimento de água; variação de renda.

\section{Abstract}

This work aimed to investigate the role of income variation on household water consumption supplied by the dealership (in this case, the water supply and sanitation services of Minas Gerais, Brazil - Copasa) in the urban area of Belo Horizonte, based on data spanning a period of 35 months (from August 2003 to June 2006). For this, data of the Monthly Employment Survey (PME, acronym in Portuguese) of the Brazilian Institute of Geography and Statistics (IBGE, acronym in Portuguese) were used, comprising 3,100 households with their 10,200 dwellers, and the household water consumption of the 6 operatinal districts of the Copasa. The household water consumption data were defined in order to allow the water consumption observation period to coincide with the social economic data. The results pointed out clearly that the household water consumption is strongly linked with the economical condition of the served population. This aspect was evident by means of the observation of spatial distribution and water consumption scattered related to the social economic characteristics and was supported by the highest coefficients of determination $\left(R^{2}>0.8\right)$ obtained and the predictable water consumption saturation for the more prosperous social economic classes.

Key-words: water consumption; household water consumption; water supply system; income variation. 


\section{Introdução e justificativa}

Aliada à crescente urbanização da população brasileira, estimada pelo Instituto Brasileiro de Geografia e Estatística (IBGE) em $82 \%$ no último censo (2000), as desigualdades socioeconômicas têm imposto às concessionárias dificuldades na gestão dos sistemas de abastecimento de água. Tais desigualdades acabam por desaguar na desuniformidade espacial da distribuição dos serviços de saneamento no país. Em contexto similar, em diversos centros urbanos brasileiros a população vivencia intermitência no abastecimento de água decorrente do aumento da demanda, com alguma frequência também causada pelo uso irracional do recurso hídrico.

$\mathrm{Na}$ estimativa da vazão de demanda para implantação ou, mais usualmente, ampliação dos sistemas de abastecimento de água visando a elevar o espectro da população abastecida, tornase crucial uma estimativa acurada do consumo residencial per capita. Dentre os principais fatores intervenientes no consumo domiciliar comumente elencados na literatura técnica - clima, percentual de hidrometração, valor da tarifa, pressões dinâmicas e estáticas na rede de distribuição, qualidade da água, entre outros -, as características socioeconômicas da população abastecida parecem adquirir papel de relevo.

Alguns estudos corroboram essa assertiva. Monitoramento realizado durante dez meses em nove bairros da região metropolitana de Belo Horizonte, abrangendo cinco classes socioeconômicas - alta (1), média alta (2), média (2), média baixa (2) e baixa (2) -, apontou correlações significativas entre o consumo per capita e a renda per capita $\left(R^{2}=0,942\right)$, a área do lote $\left(R^{2}=\right.$ $0,887)$ e o número de vasos sanitários $\left(R^{2}=0,810\right)$ (CAMPOS; VON SPERLING, 1997).

A partir de amostra ainda mais ampla de 96 municípios mineiros, com população abastecida inferior a 300 mil habitantes, estudo concluiu que a renda per capita constitui bom indicador para estimativa do consumo per capita de água (FERNANDES et al, 2005). Os resultados dessa pesquisa culminaram com coeficientes de determinação significativos, considerando a amplitude e a heterogeneidade da amostra, relacionando o consumo per capita à renda per capita $\left(\mathrm{R}^{2}=0,524\right)$ e ao Índice de Desenvolvimento Humano Municipal (IDH-M) $\left(\mathrm{R}^{2}=0,567\right)$.

Às características socioeconômicas da população associa-se o valor da tarifa de água praticado pela concessionária mesmo nos países desenvolvidos. Na região Sudoeste da França, a magnitude da tarifa tem concorrido para o crescimento de formas alternativas de abastecimento em detrimento do acesso à água tratada fornecida pelas concessionárias. A despeito dos riscos à saúde, diversos consumidores da região têm optado pela perfuração de poços rasos, pela recirculação de águas cinzas ou pelo aproveitamento de água de chuva, como forma de reduzir o custo do abastecimento doméstico (MONTGINOUL, 2005).
Evidentemente que a questão do custo da tarifa de água, como forma de remuneração para concessionária dos investimentos de implantação e de operação dos sistemas de abastecimento, também é afeita aos países em desenvolvimento. Proposições menos convencionais de abastecimento para as populações de baixíssimo poder aquisitivo têm sido elaboradas visando a ampliar a cobertura de tais serviços. Esses novos paradigmas fiam-se basicamente na formação de cooperativas que viabilizariam a construções de chafarizes públicos como alternativa ao alto custo de implantação das redes de distribuição (MARA; ALABASTER, 2008). Essa proposição guarda semelhança aos sistemas condominiais de esgotos implantados em diversas localidades do país no início da década de 1980.

De forma geral, verifica-se maior consumo per capita de água nos países de maior Produto Interno Bruto (PIB). Dados do Banco Mundial testificam essa afirmativa ao apontarem para consumos per capita médios de 305 e 215 L/hab.dia para os países de renda alta e média, respectivamente. Em semelhante perspectiva, eventual aumento das condições socioeconômicas haverá de repercutir em elevação da demanda de água. Tal se deu, por exemplo, na Holanda após construção de conjuntos habitacionais para uma comunidade de baixa renda, proporcionando aumento da ordem de 30\% no consumo per capita de água (FERREIRA; MARTINS, 2005)

A relação entre a renda da população abastecida - ou, em outras palavras, o seu poder de compra associado ao valor da tarifa e o consumo de água reverte ao conceito de elasticidade demandapreço. Esse paradigma atesta que, mantidas inalteradas as demais variáveis, a demanda de um determinado bem diminui quando seu preço aumenta, como de alguma maneira o mencionado comportamento dos consumidores franceses atesta.

Visando avaliar uma possível inelasticidade demanda-preço em relação à água consumo, o estudo estimou coeficientes para uma função de demanda baseada em parâmetros relacionados à variação da tarifa cobrada pela água na cidade de Curitiba (PIZAIA; JUNGLES, 2003). Os resultados apontaram a existência de uma elasticidade que refletia uma relação no sentido de quanto maior fosse o preço da água, menor seria a quantidade demandada.

Com o mesmo intuito, outro estudo, fundamentado nos dados de consumo de outra cidade paranaense (Paranavaí), também apontou a variável preço como independente, que explica significativamente o consumo de água, apresentando significativa correlação, porém negativa (SACHET, 2004). A fim de melhor entender o mecanismo do consumo residencial de água e ajustar um modelo para predição da demanda, empregou-se regressão linear múltipla a partir de variáveis como número de economias, temperatura densidade pluviométrica e preço da água. A elasticidade, quando se considerou o poder de compra da água por parte da população, 
ficou evidente, recomendando-se inserção de uma variável relativa à renda familiar nos próximos estudos.

No contexto industrial, Féres et al. (2005), a partir de modelos econométricos, estimaram a participação de gastos com insumos para dez distintas tipologias industriais na região do Vale do Paraíba (SP). Em seguida, do setor têxtil ao de metalurgia, calcularam-se as elasticidades demanda-preço, as quais apresentaram sinais negativos em todos os casos, indicando assim que dado um aumento no preço da água, respectiva redução de sua demanda seria acarretada. As maiores elasticidades, setor de alimentos e bebidas $(-0,82 \%)$ e de papel e celulose $(-0,76 \%)$ apontam que um aumento de $1 \%$ na tarifa de água acarretaria redução na demanda ou, mais provavelmente, repasse ao custo final do produto de equivalente magnitude.

Nesse contexto, o presente artigo abordou a variação do consumo domiciliar de água com base na variação da renda utilizando-se de análise estatística univariada, pois descrição mais ampliada da função consumo de água exigiria a adoção de tratamento estatístico de base multivariada.

Por fim, além da elasticidade demanda-preço evidenciada nas pesquisas citadas, mesmo de forma inversa, essa premissa coaduna-se com a hipótese principal do presente estudo de avaliar o impacto do aumento de renda da população abastecida no consumo domiciliar de água.

\section{Representatividade socioeconômica de Belo Horizonte}

A definição do universo da pesquisa norteou-se na similaridade de diversos indicadores econômicos, sociais e relacionados ao saneamento entre o Estado de Minas Gerais e o restante do país, conforme denota a Tabela 1 .
De forma análoga, a definição pelo sistema de abastecimento de água de Belo Horizonte pautou-se na situação mediana que diversos indicadores socioeconômicos e de saneamento básico do município apresentam em relação aos de outras capitais brasileiras. Essa afirmativa é corroborada pela Tabela 2 .

No que tange às características socioeconômicas, adotouse a definição das classes sociais estabelecida pelo Instituto de Economia da Universidade Estadual de Campinas (UNICAMP, 2005), apresentada na Tabela 3. A escala de classes estabelecida pelo Instituto de Economia da Unicamp é amplamente aceita pela comunidade econômica, sendo coincidente com a classificação proposta pela Associação Brasileira de Empresas de Pesquisa (ABEP) por meio do Critério de Classificação Econômica Brasil. Esse critério foi construído para definir grandes classes que atendam às necessidades de segmentação por poder aquisitivo para a maioria das empresas (ABEP, 2007). Infere-se, portanto, que tal critério seja mais apropriado que a classificação de faixas de renda adotada pelo IBGE, no que se refere à representação do poder de compra segmentado da população.

A partir da classificação apresentada na Tabela 4, manifesta-se claramente a mencionada representatividade de Belo Horizonte da

Tabela 3 - Classes socioeconômicas e respectivas faixas de renda domiciliar (UNICAMP, 2005)

\begin{tabular}{lc} 
Classe socioeconômica & Faixa de renda domiciliar $(\mathbf{R} \$ / \mathrm{mês})$ \\
\hline A1 & superior a $6.000,00$ \\
A2 & de $4.000,00$ a $6.000,00$ \\
B1 & de $3.000,00$ a $3.999,00$ \\
B2 & de $2.000,00$ a $2.999,00$ \\
C & de $1.000,00$ a $1.999,00$ \\
D & de 600,00 a 999,00 \\
E & inferior a 600,00 \\
\hline
\end{tabular}

Tabela 1 - Indicadores de Minas Gerais e do Brasil

\begin{tabular}{lccccc} 
Indicadores & $\begin{array}{c}\text { Cobertura por rede de } \\
\text { água (\%) }\end{array}$ & $\begin{array}{c}\text { Cobertura por rede de } \\
\text { esgoto (\%) }\end{array}$ & $\begin{array}{c}\text { Coleta de resíduos } \\
\text { sólidos (\%) }\end{array}$ & IDH-M & índice de Gini* \\
\hline Minas Gerais & 76,9 & 52,4 & 92,3 & 0,773 & 0,635 \\
Brasil & 76,1 & 40 & 91,2 & 0,766 & 0,637
\end{tabular}

Fontes: IBGE (2004) e FJP (2006).

*Índice cuja denominação reporta-se ao pesquisador italiano Corrado Gini, que traduz o grau de desigualdade de renda das populações, variando de 0 a 1,0 . À medida que o índice se aproxima da unidade, cresce a desigualdade.

Tabela 2 - Indicadores de Belo Horizonte e de algumas capitais brasileiras

\begin{tabular}{|c|c|c|c|c|}
\hline Capital/indicadores & Cobertura por rede de água (\%) & Cobertura por rede de esgoto (\%) & Acesso à coleta de resíduos sólidos (\%) & IDH-M \\
\hline Belo Horizonte & 98 & 96,9 & 98,4 & 0,839 \\
\hline São Paulo & 98,6 & 97,5 & 99,3 & 0,841 \\
\hline Rio de Janeiro & 97,8 & 96,4 & 98,7 & 0,842 \\
\hline Curitiba & 99 & 97,6 & 99,5 & 0,856 \\
\hline Porto Alegre & 97,8 & 95,4 & 99,3 & 0,865 \\
\hline Salvador & 93 & 90,2 & 93,2 & 0,805 \\
\hline Fortaleza & 88,5 & 84 & 95,7 & 0,786 \\
\hline
\end{tabular}

Fontes: IBGE (2004) e FJP (2006). 
realidade média em relação ao país e às maiores regiões metropolitanas das capitais brasileiras (ABEP, 2007).

Tais semelhanças reforçam a perspectiva de ampliação dos resultados desta pesquisa a outras cidades brasileiras. Espera-se também, em razão do mesmo motivo, que os desdobramentos futuros recomendados por este trabalho sejam facilitados, no tocante a possíveis adaptações necessárias a outras regiões metropolitanas.

\section{Características do sistema de abastecimento de água de Belo Horizonte}

O sistema de abastecimento de água de Belo Horizonte supre aproximadamente 2,4 milhões de consumidores, distribuídos em seis distritos operacionais regionais, por meio de mais de 506 mil ligações e 850 mil economias, e uma rede de distribuição de 6,4 mil km. A vazão média distribuída é da ordem $7,4 \mathrm{~m}^{3} / \mathrm{s}$, para um consumo per capita médio de 267L.hab ${ }^{-1}$. dia ${ }^{-1}$, e o percentual hidrometrado atinge quase a totalidade das economias

De acordo com a legislação que regulamenta os serviços públicos de água e esgoto prestados pela Companhia de Saneamento de Minas Gerais (Copasa), define-se como "economia" o imóvel de uma única ocupação ou subdivisão de imóvel com ocupação independente das demais perfeitamente identificável ou comprovável em função da finalidade de sua ocupação legal, dotado de instalação privativa ou comum para uso dos serviços de abastecimento de água ou de coleta de esgoto. A "ligação" de água consiste na conexão do ramal predial de água à rede pública de distribuição.

A Copasa, como a maioria das concessionárias, divide suas economias em quatro categorias: residencial, comercial, industrial e pública. A categoria residencial é a economia ocupada exclusivamente para moradia. A comercial é aquela ocupada para o exercício de atividade de compra, venda ou prestação de serviços, ou para o exercício de atividade não classificada nas outras categorias. A industrial é a ocupada para o exercício de atividade classificada como tal pelo IBGE. Por fim, a categoria pública consiste na economia ocupada para o exercício de atividades de órgãos da administração direta do Poder Público, autarquias e fundações. Também são incluídos nessa categoria hospitais públicos, asilos, orfanatos e demais instituições de caridade, albergues, instituições religiosas, organizações cívicas e políticas, e entidades de classe e sindicais.

O sistema de abastecimento de Belo Horizonte divide-se em seis distritos regionais, cujas principais características estão apresentadas na Tabela 5.

\section{Objetivos}

\section{Geral}

$\mathrm{O}$ cerne desta pesquisa consistiu em determinar o efeito que a variação da renda das famílias exerce sobre o consumo de água tratada fornecida pela concessionária (Copasa) no município de Belo Horizonte, ao longo de um histórico de 35 meses, abrangendo o período de agosto de 2003 a junho de 2006.

\section{Específicos}

Os principais objetivos específicos podem ser assim enunciados:

Tabela 4 - Distribuição da população (\%) entre as classes socioeconômicas no país e em seis regiões metropolitanas

\begin{tabular}{|c|c|c|c|c|c|c|c|}
\hline Classes socioeconômicas & Brasil & Belo Horizonte & Salvador & Recife & Rio de Janeiro & São Paulo & Porto Alegre \\
\hline A1 & 1 & 1 & 1 & 1 & 1 & 1 & 1 \\
\hline $\mathrm{A} 2$ & 5 & 5 & 4 & 4 & 4 & 6 & 5 \\
\hline B1 & 9 & 8 & 6 & 5 & 9 & 10 & 10 \\
\hline B2 & 14 & 13 & 11 & 8 & 14 & 16 & 16 \\
\hline$C$ & 36 & 37 & 29 & 26 & 38 & 39 & 35 \\
\hline $\mathrm{D}$ & 31 & 32 & 39 & 42 & 26 & 31 & 28 \\
\hline$E$ & 4 & 4 & 10 & 14 & 2 & 2 & 5 \\
\hline
\end{tabular}

Fonte: ABEP, 2007.

Tabela 5 - Características dos seis distritos operacionais do sistema de abastecimento de água de Belo Horizonte

\begin{tabular}{|c|c|c|c|c|c|}
\hline Distrito Operacional (Sigla) & $\begin{array}{c}\text { População abastecida } \\
\text { (habitantes)* }\end{array}$ & $\begin{array}{l}\text { Número de } \\
\text { ligações** }\end{array}$ & Área $\left(\mathrm{km}^{2}\right)$ & IDH-M*** & Índice de Gini \\
\hline Sul (DTSL) & 441.404 & 182.525 & 31,53 & 0,914 & 0,57 \\
\hline Sudoeste (DTSO) & 258.007 & 85.938 & 53,51 & 0,787 & 0,47 \\
\hline Oeste (DTOE) & 352.727 & 120.038 & 32,39 & 0,853 & 0,61 \\
\hline Noroeste (DTNO) & 437.077 & 150.479 & 71,37 & 0,853 & 0,55 \\
\hline Nordeste (DTNE) & 480.137 & 159.351 & 61,01 & 0,787 & 0,49 \\
\hline Leste (DTLE) & 436.837 & 147.362 & 68,11 & 0,832 & 0,44 \\
\hline
\end{tabular}

*Estimada em março de 2006.

**Incluindo todas as categorias e estimada para março de 2006

***Média estimada para março de 2006.

Fonte: Fundação João Pinheiro (FJP), 2006 - Companhia de Saneamento de Minas Gerais (Copasa), 2006. 
i) estabelecer correlações entre as características socioeconômicas da população amostrada e o consumo doméstico de água;

ii) quantificar a demanda de água por habitante e por região, avaliando-se a influência da estrutura familiar, caracterizada pela classe social, renda e número de moradores de cada domicílio amostrado;

iii) identificar as "funções demanda", e suas elasticidades, para o consumo de água segundo o nível da renda e outras variáveis do município de Belo Horizonte que, individualmente ou em conjunto, se mostrarem intervenientes no processo.

\section{Metodologia}

\section{Considerações iniciais}

Para consecução da pesquisa utilizou-se mesmo universo amostral definido pela Pesquisa Mensal de Emprego (PME) realizada pelo IBGE em seis regiões metropolitanas do país. Inicialmente, tencionava-se obter as informações advindas dos questionários da PME, em nível de microdados nos quais constavam o logradouro e as respectivas variáveis socioeconômicas. De posse da amostra de logradouros, obter-se-iam os dados de consumo das residências unifamiliares junto à Copasa. Todavia, alguns meses após o envio da correspondência de solicitação dos dados, ambos os órgãos negaram a cessão das informações com esse grau de detalhamento devido à quebra do sigilo cadastral.

A solução encontrada, para que se pudesse suprir a falta de identificação dos informantes e manter uma qualidade mínima de confiança e representatividade, foi a utilização da própria PME do IBGE para Belo Horizonte. Assim, os microdados foram tratados de forma agregada segundo os bairros da Prefeitura Municipal e, posteriormente, relacionando-os aos distritos operacionais da Copasa, pois para esses últimos havia disponibilidade histórica de consumos agregados para a categoria residencial.

Embora a estratégia de agregação dos microdados da PME por distritos operacionais possa ensejar certa incoerência no tocante à obtenção dos indicadores socioeconômicos médios e sua associação para cada nível de consumo per capita, cabe ressaltar que uma suposta redução da especificidade individual dos informantes justifica-se como única alternativa viável ao desenvolvimento da pesquisa proposta. Adicionalmente, emerge a perspectiva de ampliação da confiabilidade decorrente da maior robustez dos dados da amostra.

Adicionalmente, devido às significativas correlações apontadas pelos resultados obtidos, pode-se inferir que as desuniformidades de renda ou tipologias construtivas das populações existentes dentro de cada distrito tornam-se menos relevantes quando comparadas à magnitude do universo amostral. Essa inferência pode ser corroborada quando se observam os distintos valores IDH-M apresentados na Tabela 5. Ainda dentro desse raciocínio, os baixos índices de Gini também mostrados na Tabela 5 apontam no sentido de uma aceitável uniformidade de renda dentre os distritos estudados.

Reitera-se que o consumo de água domiciliar per capita representou apenas os volumes micromedidos das economias residenciais, não se incorporando consumos relativos às atividades comerciais, públicas e industriais. Com esse entendimento, pretendeu-se garantir o adequado relacionamento entre renda e consumo de água de cada região da Cidade, evitando-se a influência dos gastos por consumidores em regiões distintas às de sua moradia.

Por fim, as comparações entre renda e consumo de água passaram a ser feitas segundo cada bairro que compõem os respectivos distritos operacionais da Copasa. Se, por um, lado esse caminho levaria a um suposto questionamento relativo à imprecisão devido ao fato de se estar trabalhando com indicadores médios de renda e de consumo, por outro, possibilitou o tratamento dos microdados de forma automatizada, utilizando-se amostras mais representativas, além de ferramental estatístico mais produtivo e seguro, culminando em resultados mais confiáveis e robustos.

\section{Obtenção dos dados da PME}

Selecionaram-se os dados socioeconômicos da PME que cobrissem o mesmo período dos dados disponibilizados pela Copasa relativos ao consumo de água, de agosto de 2003 a junho de 2006. Os microdados da PME são os dados primários da pesquisa em seu nível menos agregado, contendo todas as variáveis do questionário, com exceção das identificações de cada informante. Cada arquivo de microdados apresentava dados mensais para as 6 regiões metropolitanas, para o total aproximado de 37.200 domicílios amostrados. Cada arquivo mensal continha cerca de 105 mil registros, representando 187 variáveis cada um.

Os microdados da pesquisa foram disponibilizados pelo IBGE em forma digital por meio de discos compactos (CD). Cada CD continha os 12 arquivos mensais para cada uma das 6 regiões metropolitanas cobertas pela pesquisa, para um determinado ano de referência.

O tamanho da amostra da PME para a região metropolitana de Belo Horizonte atingiu a faixa de 6.700 domicílios com seus 19.200 moradores abrangidos mensalmente pelas entrevistas, sendo que especificamente em Belo Horizonte a amostra contemplou 3.100 domicílios com, aproximadamente, 10.200 moradores abarcados mensalmente pela pesquisa. Considerou-se, por consequência, que o plano amostral adotado pelo IBGE para realização da PME seria significativo para apontar a renda média e os demais indicadores referentes a cada distrito operacional do sistema de abastecimento de água do município de Belo Horizonte.

Seguindo a íntegra das proporções amostrais do IBGE, calcularam-se os rendimentos mensais per capita, número médio de 
moradores por domicílio, idade e grau de instrução, para que, em seguida, tais indicadores fossem consolidados e confrontados com os dados de consumo de água residencial de cada distrito operacional, fornecidos pela Copasa.

\section{Obtenção dos dados de consumo domiciliar de água}

No tocante ao consumo de água, utilizou-se conceituação compatível. Devido a questões internas relacionadas aos sistemas informatizados, a disponibilidade dos dados de consumo residencial de água, agregados pelos mencionados distritos operacionais da Copasa, ocorreu apenas a partir agosto de 2003. Assim, para que o período de observação fosse coincidente ao dos dados socioeconômicos da PME, foram obtidos os consumos no intervalo de agosto de 2003 a junho de 2006, expressos em $\mathrm{m}^{3}$ /mês.

\section{Histórico das tarifas praticadas pela Copasa}

A fim de se estabelecer uma correta comparação entre a renda e o custo da água tratada ao longo do período amostrado, obteve-se junto à Copasa a evolução das tarifas residenciais praticadas, para que se pudesse determinar o valor relativo da água no decorrer do período abordado por esta pesquisa - objetivando a determinação da renda per capita deflacionada -, estabelecendo-se o real poder de compra por parte da população consumidora. Consideraram-se como base as tarifas mínimas praticadas, pois as tarifas mais elevadas, normalmente aplicadas a consumidores enquadrados em faixas de maiores volumes consumidos, em todos os casos, são especificamente maiores. Ou seja, nas faixas mais elevadas o valor cobrado já contempla um maior preço para cada $\mathrm{m}^{3}$ consumido, incentivando dessa forma o consumo racional do recurso. As cobranças mínimas foram aplicadas conforme a Tabela 6. Cabe ressaltar que os valores já expressam o custo total, incluindo o abastecimento de água e a coleta de esgoto residencial.

Para determinar o real poder de aquisição da população, os rendimentos aferidos foram ajustados de forma relativa ao crescimento do custo médio da tarifa mínima mensal, aplicando-se os índices de inflação. Considerou-se como marco inicial o preço unitário em agosto de 2003, a partir do qual o rendimento da população viria ser deflacionado conforme índices do valor relativo da água. Dessa forma, a deflação dos rendimentos se dá especificamente em relação

Tabela 6 - Evolução da tarifa mínima para categoria residencial

\begin{tabular}{lcc} 
Ano & Tarifa normal $(\mathrm{R} \$)^{*}$ & Tarifa social $(\mathrm{R} \$)^{* *}$ \\
\hline 2003 & 19,16 & 9,38 \\
2004 & 20,98 & 10,26 \\
2005 & 25,46 & 11,48 \\
2006 & 24,9 & 11,14
\end{tabular}

*Tarifa mínima aplicável a consumos mensais inferiores a $6 \mathrm{~m}^{3}$.

**Tarifa aplicável a economias exclusivamente residenciais com consumo mensal inferior a $15 \mathrm{~m}^{3} \mathrm{e}$ em imóveis com área útil inferior a $44 \mathrm{~m}^{2}$.

Fonte: Copasa, 2006. ao insumo água. Índices mais abrangentes como o Índice Nacional de Preços ao Consumidor Amplo (IPCA) do IBGE levam em conta um vetor de variação de preços de uma cesta típica de serviços e produtos para consumidores com renda entre 1 e 40 salários mínimos, refletindo, portanto, a variação do conjunto. A aplicação dos fatores constantes na Tabela 7 (coluna Índice médio) gerou os rendimentos familiares denominados "rendas deflacionadas" em relação à variação do custo da água.

\section{Tratamento dos dados}

A preparação dos dados socioeconômicos consistiu em, inicialmente, a partir do arquivo mensal de microdados da PME, proceder à entrada das informações ao software Statistical Package for the Social Sciences (SPSS), empregando a rotina desenvolvida e depois tratá-los conforme desejado. Assim, foram lidas do arquivo original de microdados apenas as variáveis pertinentes ao foco deste trabalho. Após a leitura e entrada dos microdados da pesquisa completa, procedeu-se à rotina de seleção dos dados de interesse.

Como o trabalho em questão abordou o município de Belo Horizonte, fez-se necessário filtrar as entrevistas que atendessem tal quesito. Além disso, nessa etapa foram realizadas as adições dos bairros, regiões administrativas e distritos operacionais para cada informante entrevistado. Na sequência, calcularam-se os indicadores socioeconômicos agregados por distrito operacional da Copasa. Os indicadores médios foram determinados a partir das médias calculadas dentre todas as entrevistas realizadas em cada bairro integrante de cada um dos seis distritos operacionais.

O procedimento completo foi repetido para cada 1 dos 35 meses do período amostrado pela pesquisa. Assim, viabilizou-se a montagem de séries históricas referentes aos indicadores socioeconômicos de cada distrito operacional no período de observação.

Montadas as séries históricas das variáveis, iniciaram-se os processos de análise e cruzamento dos dados. Realizaram-se dez comparações entre os conjuntos de dados relativos às rendas da população e aos consumos de água, conforme enunciado pela Tabela 8 .

Para as comparações listadas na Tabela 8 efetuaram-se ainda regressões logarítmicas, geométricas, exponenciais e lineares para cada defasagem mensal de variáveis consideradas, determinando-se os respectivos coeficientes de determinação $\left(R^{2}\right)$. Tencionou-se avaliar a relação de "causa-e-efeito" e seu respectivo aspecto temporal, ou em

Tabela 7 - Índices de deflação a serem aplicados aos rendimentos mensais per capita

\begin{tabular}{lccc} 
Ano & Tarifa normal & Tarifa social & índice médio \\
\hline 2003 & 1 & 1 & 1 \\
2004 & 0,913 & 0,914 & 0,914 \\
2005 & 0,753 & 0,817 & 0,785 \\
2006 & 0,770 & 0,842 & 0,805 \\
\hline
\end{tabular}

Fonte: Elaboração própria, 2006. 
outras palavras, a perspectiva (ou consolidação) de que um aumento na renda familiar possa elevar o consumo de água. Nessa premissa, além da observação histórica realizada, aplicaram-se defasagens entre os meses de apuração da renda e os meses dos volumes micromedidos para que se pudesse avaliar o melhor tempo de resposta entre as duas variáveis. As defasagens entre os dados de cada variável cruzada foram, além do próprio mês de referência ( $\mathrm{m})$, os meses m-2, m-1, $m+1, m+2$ e $m+3$.

Em face dos formatos dos gráficos de dispersão obtidos nos resultados, optou-se ainda em analisar o conjunto de dados excluindo-se a classe com renda mais abastada (classe A), com rendimentos mensais superiores a $\mathrm{R} \$ 6.000,00$, uma vez que apresentou consumos de água elevados e com maior dispersão em relação às demais classes. Para essa situação de exclusão de parte da amostra, as mesmas comparações entre variáveis listadas na Tabela 8 foram efetuadas (análises de 6 a 10), porém, conforme menção anterior, considerando-se dados referentes à população com rendimento mensal per capita inferior a $\mathrm{R} \$ 600,00$ para o caso de renda deflacionada, e $\mathrm{R} \$ 650,00$ para o caso de renda absoluta.

\section{Análise estatística dos dados}

A leitura, classificação, manipulação, armazenamento e cálculos estatísticos dos microdados da PME realizaram-se por meio do software SPSS. A qualidade da aderência dos dados aos modelos foi avaliada por meio da técnica denominada leave-one-out. Nessa técnica, de forma aleatória, extraem-se parcelas da amostra com tamanhos aproximadamente iguais entre si, calculando-se seus desvios-padrão e comparando-se respectivamente os resíduos e erros relativos à amostra principal e à parcela extraída. Para comprovação da qualidade da aderência, os resíduos obtidos da amostra principal devem ser menores que os erros da parcela de dados extraída; vale afirmar, a amostra principal deve sempre representar melhor o modelo do que qualquer parcela extraída da mesma. Em todos os casos testados durante a análise dos dados, tal exigência foi atendida.

\section{Resultados e discussão}

\section{Análise do comportamento temporal das variáveis}

Inicialmente, tomaram-se os volumes residenciais micromedidos ao longo do período de observação para que se pudesse avaliar o comportamento do consumo por parte de cada distrito operacional. A partir dessa análise preliminar, denota-se que em todos os distritos operacionais houve oscilações no consumo residencial de água, mas sem constituir uma tendência definida de crescimento ou redução ao longo do período amostrado. Cada distrito apresentou oscilações positivas e negativas em torno de um volume médio
Tabela 8 - Análises comparativas efetuadas entre as variáveis

\begin{tabular}{|c|c|c|}
\hline Análise & Variável independente & Variável dependente \\
\hline 1 & Renda per capita deflacionada & Consumo residencial \\
\hline 2 & Renda per capita deflacionada & Consumo total \\
\hline 3 & Renda per capita deflacionada & Consumo total per capita \\
\hline 4 & Renda per capita absoluta & Consumo residencial per capita \\
\hline 5 & Renda per capita deflacionada & Consumo residencial per capita \\
\hline 6 & $\begin{array}{l}\text { Renda per capita deflacionada } \\
\text { até } \mathrm{R} \$ 600,00\end{array}$ & Consumo residencial \\
\hline 7 & $\begin{array}{l}\text { Renda per capita deflacionada } \\
\text { até } \mathrm{R} \$ 600,00\end{array}$ & Consumo total \\
\hline 8 & $\begin{array}{l}\text { Renda per capita deflacionada } \\
\text { até } \mathrm{R} \$ 600,00\end{array}$ & Consumo total per capita \\
\hline 9 & $\begin{array}{l}\text { Renda per capita absoluta até } \\
\mathrm{R} \$ 650,00\end{array}$ & Consumo residencial per capita \\
\hline 10 & $\begin{array}{l}\text { Renda per capita deflacionada } \\
\text { até } R \$ 600,00\end{array}$ & Consumo residencial per capita \\
\hline
\end{tabular}

Fonte: Elaboração própria, 2006.

que se possa atribuir-lhes. Ressalta-se também o grande consumo do Distrito Sul (apenas o quarto em população abastecida), em torno dos $2.300 .000 \mathrm{~m}^{3} / \mathrm{mês}$, em contraposição ao consumo reduzido do Distrito Sudoeste, da ordem dos $850.000 \mathrm{~m}^{3} / \mathrm{mês}$.

A próxima variável observada ao longo do período foi o rendimento absoluto da população. O indicador adotado para essa análise foi o rendimento mensal médio per capita em cada um dos distritos operacionais, conforme mostrado pela Figura 1. Com objetivo meramente comparativo, apresenta-se também a evolução do salário mínimo oficial estabelecido anualmente pelo Governo Federal.

$\mathrm{Da}$ análise da Figura 1 depreende-se que todos os distritos apresentaram ganhos de rendimento per capita no período de março de 2002 a junho de 2006. Os ganhos absolutos traduzem um crescimento médio da renda da população aproximado de 80 a 110\%. Cabe salientar que o ganho absoluto não contempla a inflação registrada nos preços dos insumos. Também se pode afirmar que tais ganhos superaram o crescimento do salário mínimo no período, este da ordem de 50\%. Vale ainda mencionar que, no período considerado, o PIB do país apresentou crescimentos reais, descontada a inflação, de 1,1\% (2003), 5,7\% (2004), 3,2\% (2005) e 4,0\% (2006), totalizando algo em torno de $14,7 \%$.

Para que os indicadores per capita mantivessem sua fidedignidade, não se poderia deixar de considerar a evolução populacional de cada distrito durante o período de observação da pesquisa. Como melhor alternativa, adotaram-se as estimativas populacionais elaboradas pela própria Copasa, uma vez que já se apresentavam segmentadas por distritos, e em números absolutos contemplavam os residentes atendidos pela rede de distribuição de água. Tais estimativas populacionais apontaram tendência similar entre os seis distritos operacionais.

A estimativa da evolução populacional possibilitou proceder ao cálculo do consumo per capita micromedido, incluindo somente a categoria residencial, segundo cada distrito operacional de Belo 
Horizonte. Considerou-se que essa variável derivada fosse a que melhor se relacionaria aos possíveis indicadores socioeconômicos intervenientes, e mais precisamente ao rendimento per capita da população. Na Figura 2, apresenta-se a evolução desse parâmetro derivado dos dados obtidos, para o período em análise.

Ao contrário do aumento do consumo de água total, ao se avaliar o consumo per capita percebe-se que, apesar das oscilações positivas e negativas, houve ligeira redução em todos os distritos, em termos relativos de, aproximadamente, menos de 4\% no período amostrado.
Observa-se também uma redução dos valores relativos aos picos máximos e mínimos de consumo. No entanto, percebe-se uma inversão de posições relativas, se comparados os consumos registrados entre os distritos, no caso do consumo total e no consumo per capita. Tal constatação comprova que não só a variável população interfere no consumo de água, mas também outros fatores relativos a cada distrito em particular. Adicionalmente, as políticas da Copasa voltadas à redução de consumo, por princípios de tratamento isonômico, não variam territorialmente dentro do município. Interessante ainda ressaltar que

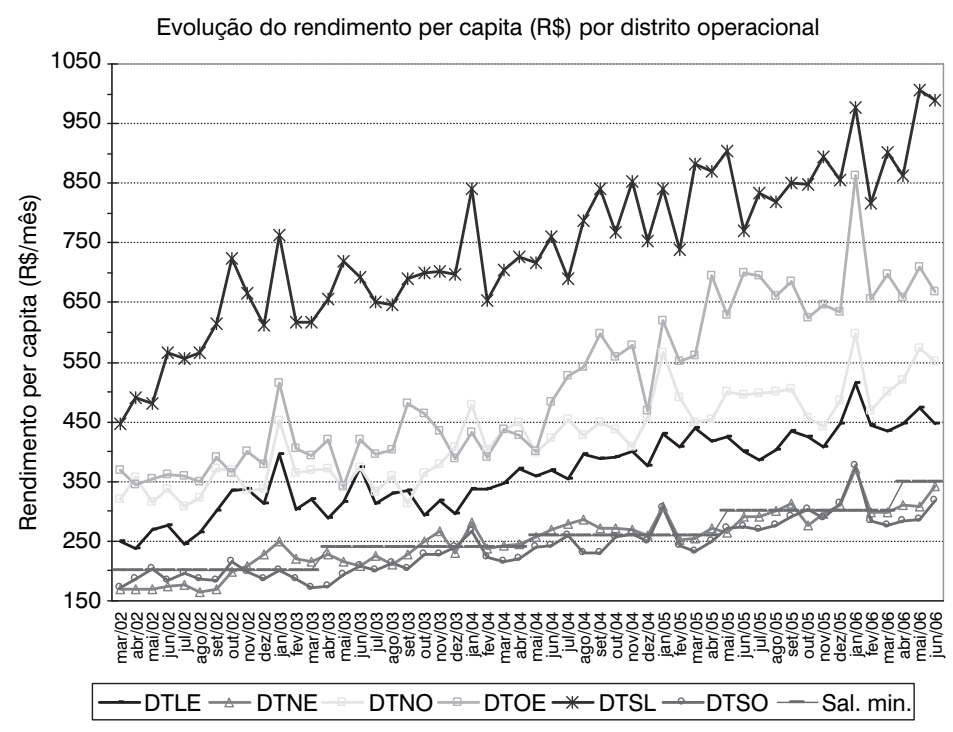

DTLE: Distrito operacional Leste; DTNE: Distrito operacional Nordeste; DTNO: Distrito operacional Noroeste; DTOE: Distrito operacional Oeste; DTSL: Distrito operacional Sul; DTSO: Distrito operacional Sudoeste; Sal. min.: salário mínimo.

Fonte: Instituto Brasileiro de Geografia e Estatística (IBGE) - Pesquisa Mensal do Emprego (PME) 2002 a 2006

Figura 1 - Rendimento mensal médio per capita segundo cada distrito operacional

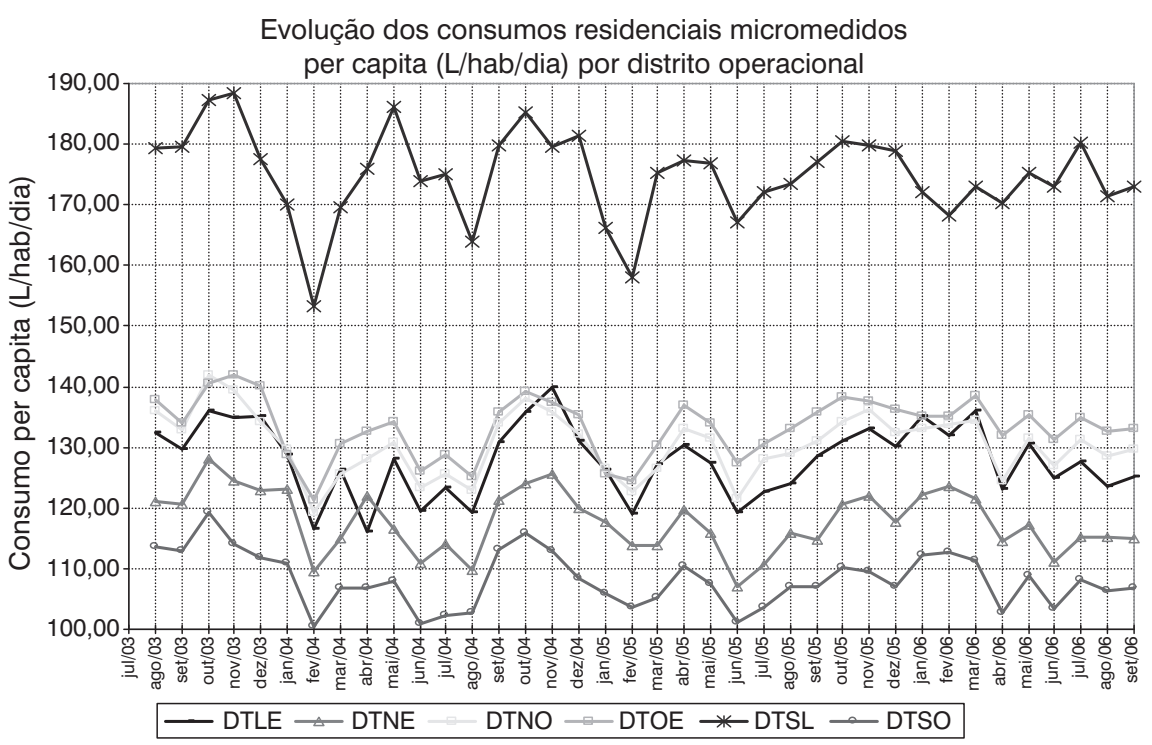

DTLE: Distrito operacional Leste; DTNE: Distrito operacional Nordeste; DTNO: Distrito operacional Noroeste; DTOE: Distrito operacional Oeste; DTSL: Distrito operacional Sul; DTSO: Distrito operacional Sudoeste.

Figura 2 - Consumo residencial per capita, segundo cada distrito operacional 
a hierarquização do consumo per capita aproxima-se à do IDH-M de cada distrito (Tabela 5), associando o maior valor desse indicador ao distrito operacional Sul. Essa tendência também foi confirmada em trabalho anterior já mencionado (FERNANDES NETO et al., 2005).

Dando sequência ao processo analítico do comportamento temporal das variáveis, passou-se a considerar o poder de compra de água por parte da população. Dessa feita, os rendimentos per capita foram recalculados para que refletissem seu real valor em relação ao custo da água, deflacionados de acordo com a inflação verificada na tarifa praticada pela Copasa (Tabela 6). Os índices médios de deflação a serem aplicados nos rendimentos per capita constam na Tabela 7 e a evolução da renda per capita deflacionada apresenta-se na Figura 3.

O exame da Figura 3 evidencia rendimentos per capita mais modestos na população abastecida dos distritos comparados aos observados na Figura 2. Nas camadas socioeconômicas inferiores, como as populações dos distritos operacionais Sudoeste, Nordeste e Leste, registraram-se ganhos da ordem de 5 a 20\%. Já nos distritos operacionais mais favorecidos financeiramente, os rendimento per capita elevaram-se de 25 a 35\%.

Esses resultados permitem afirmar que, em se referindo ao insumo água tratada em Belo Horizonte, durante o período observado, as classes sociais mais abastadas tiveram seu poder de compra de água aumentado em maior proporção que o verificado nas classes sociais menos favorecidas. Em outras palavras, caso se considerasse apenas o componente "água" como bem de consumo, a desigualdade do poder de compra da população teria aumentado nesse período em Belo Horizonte.

\section{Impacto da renda na determinação das funções demanda}

Conforme elencado nos objetivos, inferiram-se no âmbito das residências prováveis interferências no consumo causadas por mudanças nos hábitos, comportamentos ou atitudes dos moradores decorrentes da alteração dos rendimentos familiares. Como exemplo, pode-se imaginar que uma família, ao ter acesso a maior renda, adotasse práticas comportamentais que incorressem em maior frequência de banhos, lavagem de carros, preparo de alimentos, festas, limpezas da residência, dentre outras.

Após a montagem das séries históricas, procedeu-se às diversas análises comparativas entre as rendas da população e os respectivos consumos, aplicando-se as defasagens mensais entre a base referencial de cada variável. Na Figura 4 apresenta-se um exemplo dos gráficos de dispersão (nesse caso, Análise 10 da Tabela 8), e respectivos coeficientes de determinação, elaborados para cada tipo de análise listada.

A síntese dos melhores resultados obtidos nesta etapa da pesquisa é apresentada na Tabela 9, destacando-se os coeficientes de determinação mais significativos.

Dos resultados sintetizados na Tabela 9, destacam-se as significativas correlações obtidas para Análise 5 (renda per capita deflacionada versus consumo residencial per capita), cujos coeficientes de determinação para todas simulações foram superiores a 0,75 . Vale ressaltar os valores dos coeficientes de determinação obtidos com a defasagem $m+3\left(R^{2}\right.$ máximo $\left.=0,820\right)$.

Evolução do rendimento per capita deflacionado em relação ao custo da água $(\mathrm{R} \$)$ por distrito operacional

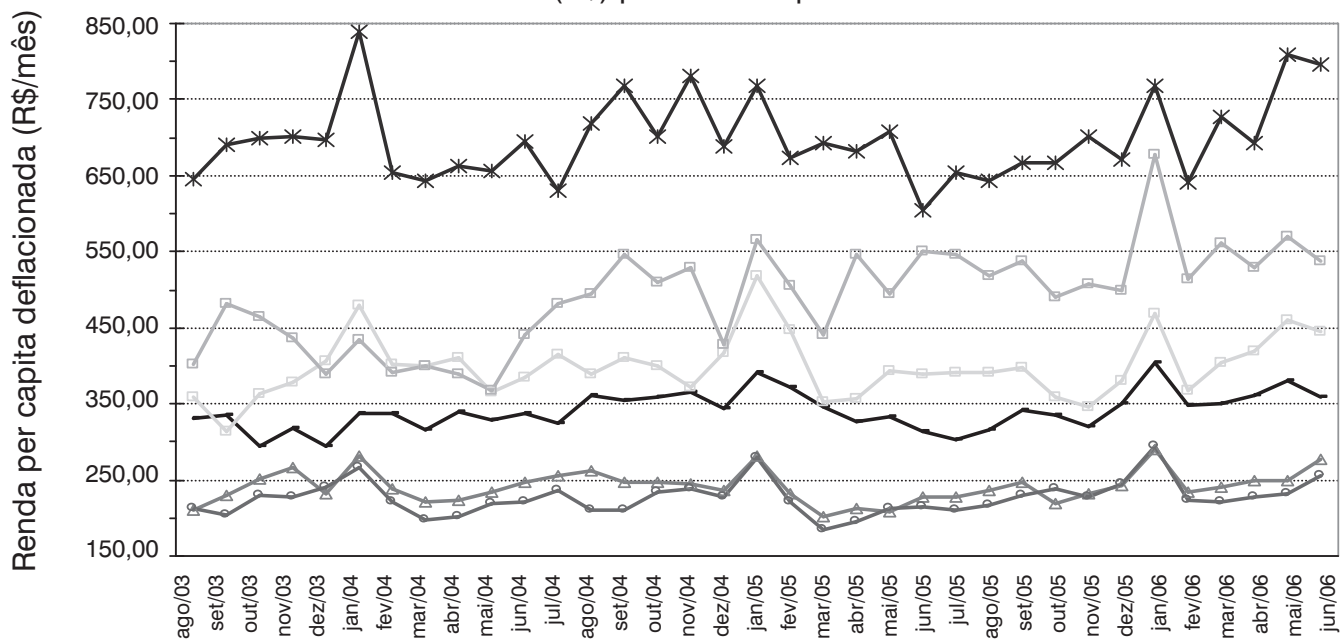

- DTLE $\multimap$ DTNE $\simeq$ DTNO $\rightleftharpoons$ DTOE $\rightarrow$ DTSL $\simeq$ DTSO

DTLE: Distrito operacional Leste; DTNE: Distrito operacional Nordeste; DTNO: Distrito operacional Noroeste; DTSL: Distrito operacional Sul; DTSO: Distrito operacional Sudoeste.

Figura 3 - Rendimento médio mensal per capita deflacionado, segundo cada distrito operacional 
Levando-se em conta os resultados dos estudos e pesquisas científicas sobre o consumo de água, o tipo de função mais indicada para representar um modelo de demanda seria o logarítmico. Tal afirmação fundamenta-se, ainda, no argumento de que a função logarítmica, além de gerar um ajuste de curva com boa aderência à dispersão dos dados, prevê uma previsível saturação do consumo nas faixas de maior rendimento per capita, dada sua característica assintótica da cauda direita da curva.

Contudo, em face da descontinuidade apresentada nos gráficos de dispersão nos quais se verificou um grupo de pontos isolados com consumos elevados relacionados a altos rendimentos per capita, poder-se-ia imaginar a possibilidade de uma correlação espúria. Assim, foram desconsiderados tais dados isolados, para que a análise se desse na faixa de dispersão contínua. Esse raciocínio leva à assunção da

Tabela 9 - Síntese das análises de correlação entre as variáveis avaliadas

\begin{tabular}{lcccc} 
Análise & Defasagem & $\mathrm{R}^{2}$ máximo & $\begin{array}{c}\text { Modelo } \\
\text { matemático }\end{array}$ & Equação* \\
\hline 1 & $\mathrm{~m}-2$ & 0,495 & Linear & $\mathrm{y}=1847,4 \mathrm{x}+84571$ \\
\hline 2 & $\mathrm{~m}-2$ & 0,667 & Linear & $\mathrm{y}=3332,1 \mathrm{x}+69669$ \\
3 & $\mathrm{~m}-2$ & 0,768 & Linear & $\mathrm{y}=0,2179 \mathrm{x}+82,642$ \\
4 & $\mathrm{~m}+3$ & 0,762 & Linear & $\mathrm{y}=0,0943 \mathrm{x}+88,071$ \\
\hline 5 & $\mathrm{~m}-2$ & 0,829 & Linear & $\mathrm{y}=0,118 \mathrm{x}+82,642$ \\
\hline 6 & $\mathrm{~m}+3$ & 0,159 & Logarítmico & $\mathrm{y}=43790 \ln \mathrm{x}-106$ \\
7 & $\mathrm{~m}+3$ & 0,233 & Logarítmico & $\mathrm{y}=552033 \ln \mathrm{x}-106$ \\
\hline 8 & $\mathrm{~m}+3$ & 0,467 & Logarítmico & $\mathrm{y}=29,464 \ln \mathrm{x}-18,539$ \\
9 & $\mathrm{~m}+3$ & 0,578 & Logarítmico & $\mathrm{y}=27,074 \ln \mathrm{x}-36,796$ \\
\hline 10 & $\mathrm{~m}+3$ & 0,661 & Logarítmico & $\mathrm{y}=28,154 \ln \mathrm{x}-39,598$
\end{tabular}

Fonte: Elaboração própria, 2006. premissa que a classe isolada seria a denominada classe social "A", a qual se comporta de forma diferente das demais. Todas as análises comparativas demonstradas anteriormente nesta pesquisa corroboraram para a interpretação de que em situações de alta renda ocorrem mudanças no padrão de consumo de água por parte da população.

Dessa forma, com a desconsideração do grupo de dados isolados, repetiram-se todas as análises comparativas a fim de se reavaliar qual seria a melhor situação representativa para os habitantes pertencentes às classes sociais E, D, C e B. Os dados remanescentes constituem, para esta pesquisa, os habitantes que, em função do número médio de moradores por domicílio, apresentam rendimento per capita igual ou inferior a $\mathrm{R} \$ 600,00$ para o caso de renda deflacionada e igual ou inferior a $\mathrm{R} \$ 650,00$ para o caso de renda absoluta. O melhor resultado dessas análises foi apresentado no exemplo da Figura 4 , confirmando o modelo logarítmico com o maior coeficiente de determinação para defasagem mensal $m+3$

Tais volumes, referentes à classe $\mathrm{A}$, foram incorporados novamente à amostra e estão mostrados na Figura 5, destacando-se circundados os demais agrupamentos sociais em termos de consumos domiciliares de água em Belo Horizonte e seus respectivos rendimentos mensais per capita.

Visando avaliar a consistência da metodologia adotada, estimouse o volume total micromedido em Belo Horizonte para o mês de dezembro de 2006, balizado na população abastecida da ordem de 2,4 milhões de habitantes. Para tal, multiplicou-se a população abastecida pertencente a cada classe social (Tabela 4) pelo consumo médio per capita da mesma classe obtido da Figura 5. Dessa forma, tem-se:

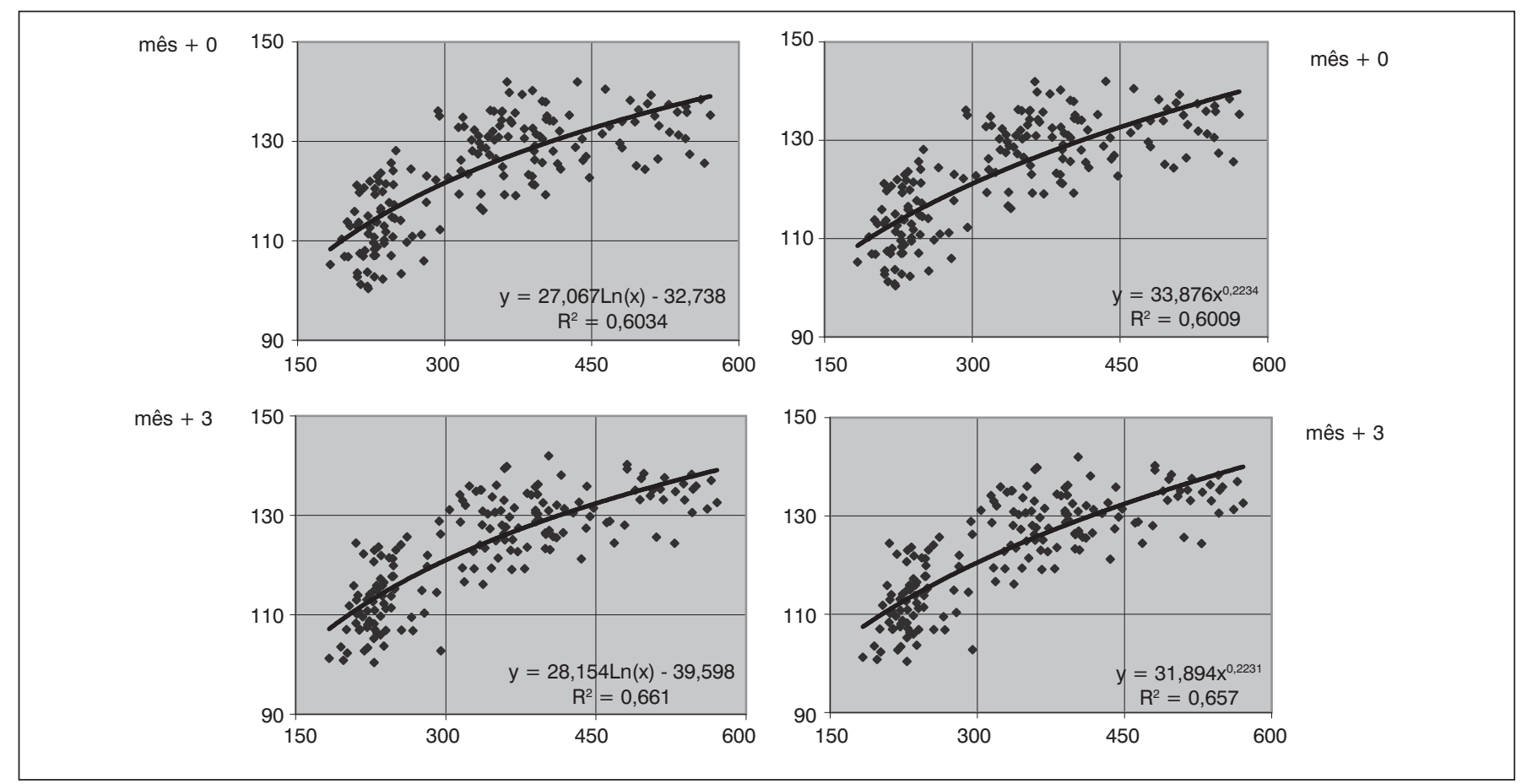

Figura 4 - Gráficos de dispersão entre renda per capita deflacionada até $\mathrm{R} \$$ 600,00 e consumo residencial per capita (abscissas em R\$/mês per capita e ordenadas em L/hab.dia) 
- População da classe E/D $\rightarrow(4 \%+32 \%)$ x 2,4 milhões $=864$ mil habitantes;

- Consumo médio da classe E/D $\rightarrow 113$ L/hab.dia;

- População da classe C $\rightarrow$ (37\%) x 2,4 milhões $=888$ mil habitantes;

- Consumo médio da classe C $\rightarrow 129$ L/hab.dia;

- População da classe B $\rightarrow(13 \%)$ x 2,4 milhões = 312 mil habitantes;

- Consumo médio da classe B $\rightarrow 134$ L/hab.dia;

- População da classe A $\rightarrow$ (14 \%) x 2,4 milhões = 336 mil habitantes:

- Consumo médio da classe A $\rightarrow 174$ L/hab.dia;

Logo, para se obter o consumo total projetado pelo modelo para a população, vem:

$\mathrm{Q}=(864$ mil $\times 113)+(888 \mathrm{mil} \times 129)+(312 \mathrm{mil} \times 134)+(336$ mil x 174)

$\mathrm{Q}=9.686 .136 \mathrm{~m}^{3} / \mathrm{mês}$.

Segundo a Copasa, o consumo micromedido residencial total em Belo Horizonte em dezembro de 2006 foi $9.951 .055 \mathrm{~m}^{3}, 2,74 \%$ superior ao estimado, corroborando a consistência da metodologia.

Portanto, para que seja viabilizada a projeção do consumo domiciliar de água em um determinado cenário socioeconômico futuro de uma região metropolitana brasileira, mantidas semelhantes as demais características de implantação urbana, como as observadas em Belo Horizonte, bastaria que se determinassem, a partir do modelo proposto (Figura 5), faixas de renda e suas respectivas médias de demanda residencial per capita. Em seguida, dimensionar-se-ia o tamanho de cada faixa de renda estipulada em função da população existente em cada uma delas, ou seja, quantificar-se-ia populacionalmente a grandeza de cada classe social adotada na projeção a ser realizada. Finalmente, por meio do produto entre as demandas médias e o número de habitantes de cada classe, obter-se-ia o volume total de água demandado para a categoria residencial da região metropolitana adotada para o estudo.

Finalmente, observou-se que no geral não há grandes variações entre os (significativos) coeficientes de determinação obtidos pelos distintos modelos matemáticos para as mencionadas variáveis renda per capita deflacionada e consumo residencial per capita, incluindo todas as classes sociais, conforme evidencia Tabela 10.

\section{Conclusões}

As análises efetuadas permitem afirmar que o consumo de água está intimamente ligado às condições socioeconômicas da população abastecida e, por conseguinte, seu poder aquisitivo em relação ao insumo "água tratada". Essa correlação contempla as condições

Tabela 10 - Coeficientes de determinação obtidos pelos modelos de regressão entre renda per capita deflacionada e consumo residencial micromedido per capita

\begin{tabular}{lccccc} 
Defasagem mensal & \multicolumn{3}{c}{ Coeficientes de determinação } & \multicolumn{2}{c}{ R2 médio } \\
\cline { 2 - 5 } & Modelo logarítmico & Modelo geométrico & Modelo exponencial & Modelo linear & 0,808 \\
$\mathrm{~m}-2$ & 0,774 & 0,799 & 0,831 & 0,829 & 0,802 \\
$\mathrm{~m}-1$ & 0,769 & 0,792 & 0,825 & 0,824 & 0,791 \\
Mês referência $(\mathrm{m})$ & 0,758 & 0,780 & 0,813 & 0,804 & 0,783 \\
$\mathrm{~m}+1$ & 0,751 & 0,773 & 0,805 & 0,819 & 0,800 \\
$\mathrm{~m}+2$ & 0,767 & 0,791 & 0,822 & 0,820 & 0,802
\end{tabular}

Fonte: Elaboração própria, 2006.

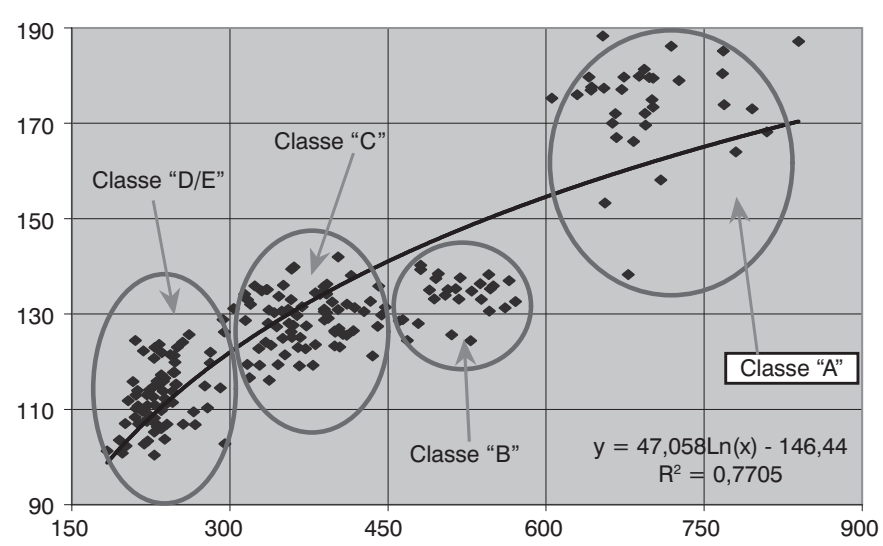

Figura 5 - Gráfico de dispersão entre renda per capita deflacionada e consumo residencial per capita para defasagem mensal m +3 (abscissa em $\mathrm{R} \$$ /mês per capita e ordenada em L/hab.dia) 
socioeconômicas da população abastecida e a política tarifária praticada pela concessionária responsável pelo abastecimento de água. Tal assertiva evidencia-se pela distribuição espacial e pela dispersão dos consumos residenciais de água em relação às características socioeconômicas de cada um dos seis distritos operacionais de Belo Horizonte.

Pela interpretação dos resultados da pesquisa, pode-se afirmar que não houve significativo impacto no consumo de água devido à evolução histórica da renda. Mesmo porque, além da limitada série histórica de dados disponibilizada pelas instituições pesquisadas, não se observou ganho relativo significante do poder de compra de água por parte da população, uma vez que o custo tarifado praticado pela concessionária sofreu incrementos e acompanhou o aumento de renda per capita apurada conjunturalmente pela PME, deixando quase sem efeito prático a tendência de variação na renda deflacionada. No entanto, quando se consideraram as diferenças de renda per capita da população residente segundo cada distrito operacional, englobando a região geográfica e seus indicadores socioeconômicos, observou-se a mencionada dimensão da influência da renda sobre o volume mensal da água consumida.

A presente pesquisa fundamentou-se nos resultados e análises regionais obtidos para o município de Belo Horizonte. No caso de uma possível continuidade do trabalho, recomenda-se uma abordagem mais individualizada, pesquisando-se o consumo de água e o rendimento em nível domiciliar. Devido ao caráter sigiloso aplicado às identificações dos informantes das pesquisas oficiais realizadas pelo IBGE, recomenda-se, alternativamente, uma pesquisa domiciliar realizada em campo, elaborada com planos amostrais desenvolvidos a partir de setores censitários que se façam representativos da área a ser estudada. Recomenda-se também a aplicação da metodologia desenvolvida neste trabalho em outras regiões metropolitanas brasileiras ou internacionais, para que se possa validar um modelo que responda a qualquer cenário socioeconômico urbano projetado.

\section{Agradecimentos}

Ao Instituto Brasileiro de Geografia e Estatística (IBGE) e à Companhia de Saneamento de Minas Gerais (Copasa), pela cessão dos dados utilizados na pesquisa, e à Fundação de Amparo à Pesquisa de Minas Gerais (Fapemig) no contexto do Programa Pesquisador Mineiro (Processo n 00129/09).

\section{Referências}

ABEP (Associação Brasileira de Empresas de Pesquisa). Critério de Classificação Econômica Brasil. Disponível em: http://www.abep.org/ novo/Content.aspx?SectionID=84. Acesso em: 17 ago. 2007.

CAMPOS, H.M.; VON SPERLING, M. Proposição de Modelos para Determinação de Parâmetros de Projeto para Sistemas de Esgotos Sanitários com Base em Variáveis de Fácil Obtenção. 19 Congresso brasileiro de engenharia sanitária e ambiental, 1997, Foz do Iguaçu. Anais... Rio de Janeiro: ABES, 1 CD-ROM, 1997.

COMPANHIA DE SANEAMENTO DE MINAS GERAIS (COPASA). "Relatório de Indicadores Básicos Gerenciais" e "Relatório de Informações Básicas Operacionais". Belo Horizonte, MG, 2006.

FÉRES, J. G. et al. Demanda por água e custo de controle da poluição hídrica em indústrias da bacia do rio Paraíba do Sul. Simpósio Brasileiro de Recursos Hídricos, XVI, 2005, João Pessoa. Anais... Porto Alegre: ABRH, 1 CD-ROM, 2005.

FERNANDES NETO, M. L. et al. Assessing the relevance of intervening parameters on the per capita water consumption rates in Brazilian urban communities. Water Science \& Technology: Water Supply, v.1, n.5, p.9-15, 2005.

FERREIRA, P.; MARTINS, J. Crescimento econômico e consumo de água - Uma abordagem para planejamento de sistemas. $23^{\circ}$ Congresso brasileiro de engenharia sanitária e ambiental, 2005, Campo Grande. Anais... Rio de Janeiro: ABES, 1 CD-ROM, 2005.

FUNDAÇÃO JOÃO PINHEIRO (FJP). Atlas de Desenvolvimento Humano.
Belo Horizonte, 2006. Disponível em: http://www.fjp.gov.br. Acesso em: 21 set. 2007

INSTITUTO BRASILEIRO DE GEOGRAFIA E ESTATÍSTICA (IBGE). Atlas de Saneamento. Rio de Janeiro: Coordenação de Geografia: Diretoria de Geociências, 2004. 151p.

MARA, D.; ALABASTER, G. A new paradigm for low-cost urban water supplies and sanitation in developing countries. Water Policy, v.10, n.2, p.119-129, 2008.

Montginoul, M. et al. Simulating the impact of water pricing on household behaviour: the temptation of using untreated water. Water Policy, v.7, n.5 p.523-541, 2005.

PIZAIA, M. G.; JUNGLES A. E. Estimativa da função demanda residencial por água: Um estudo de caso para a metrópole de Curitiba. $22^{\circ}$ Congresso brasileiro de engenharia sanitária e ambiental, 2003, Joinville. Anais... Rio de Janeiro: ABES, 1 CD-ROM, 2003.

SACHET, M. A. C. Prognóstico de demanda de água mensal para efeito de planejamento operacional da produção de água. $11^{\circ}$ Simpósio lusobrasileiro de engenharia sanitária e ambiental, 2004, Natal. Anais... Rio de Janeiro: ABES; APRH; APESB, 1 CD-ROM, 2004.

UNIVERSIDADE ESTADUAL DE CAMPINAS (Unicamp). Classe média de Campinas empobrece. Assessoria de Comunicação e Imprensa, Unicamp, Campinas, 2005. Disponível em: http://www.unicamp.br/ unicamp/unicamp_hoje/ju/anteriores.html\#2007. Acesso em: 17 ago. 2007 